\title{
Pengembangan Aplikasi Distribusi Data Dari Aplikasi ASC Timetable Menuju Aplikasi Siakad
}

\author{
Agus Purnomo* \\ Institut Agama Islam Negeri Salatiga \\ *Email: agus.purnomo@iainsalatiga.ac.id
}

\section{Info Artikel}

Kata Kunci :

Penjadwalan, asc timetable, siakad, distribudi data

\section{Keywords :}

Scheduling, asc timetable, siakad, data distribution

\section{Tanggal Artikel}

Dikirim : 29 November 2019

Direvisi : 30 November 2019

Diterima : 30 November 2019

\begin{abstract}
Abstrak
Penjadwalan pembelajaran atau perkuliahan adalah kegiatan rumit. Inti dari penjadwalan adalah menggatur sumberdaya tenaga pendidik, ruang kelas, siswa dan waktu tidak berbenturan. Banyak software penjadwalan yang dikembangkan secara mandiri oleh institusi terkait dan ada juga yang dikembangkan oleh perusahaan komersial. Disini akan diangkat satu software penjadwalan dengan nama asc timetable. Permasalahan yang muncul adalah distribudi data dari asc timetable menuju aplikasi siakad harus dilakukan secara manual. Penyebabnya adalah tidak adanya fasilitas interkoneksi diantara keduanya. Solusi dilakukana adalah mengembangkan aplikasi penghubung yang mampu mendistribusikan data dari asc timetable menuju aplikasi siakad. Aplikasi dikembangkan berbasis teknologi web dengan bahasa pemprograman PHP dan database mysql. Produk yang dihasilkan berupa aplikasi yang mampu ektrak data $\mathrm{xml}$ asc timetable dalam format sq/ dan excel. Dari hasil uji ektrak data sebanyak 1305 jadwal perkuliahan, aplikasi yang dikembangkan mampu memberikan nilai efisiensi dan efektifitas waktu sebanyak $99 \%$ jika dibandingkan dengan metode ektrak manual.
\end{abstract}

Abstarct
Scheduling learning or lectures is a complicated activity. The essence
of scheduling is to arrange the resources of educators, classrooms,
students and non-clashing time. Many scheduling software are
independently developed by related institutions and some are
developed by commercial companies. Software discussed is asc
timetable application. The problem that arises is the distribution of data
from the asc timetable application to the Siakad application must be
done manually. The reason is the absence of interconnection facilities
between the two. The solution is to develop a liaison application that is
able to distribute data from an asc timetable application to a Siakad
application. The application is developed based on web technology
with the PHP programming language and MySQL database. The
resulting product is an application that is able to extract xmI data in sql
and excel format. From the results of the data extraction test of 1305
lecture schedules, the application developed was able to provide a
value of efficiency and time effectiveness of as much as $99 \%$ when
compared to the manual extraction method.

Scheduling learning or lectures is a complicated activity. The essence of scheduling is to arrange the resources of educators, classrooms, students and non-clashing time. Many scheduling software are independently developed by related institutions and some are developed by commercial companies. Software discussed is asc timetable application. The problem that arises is the distribution of data from the asc timetable application to the Siakad application must be done manually. The reason is the absence of interconnection facilities between the two. The solution is to develop a liaison application that is able to distribute data from an asc timetable application to a Siakad with the PHP programming language and MySQL database. The resulting product is an application that is able to extract $\mathrm{xmI}$ data in sql and excel format. From the results of the data extraction test of 1305 value of efficiency and time effectiveness of as much as $99 \%$ when compared to the manual extraction method. 


\section{PENDAHULUAN}

Instansi pendidikan dari mulai jenjang SD,SMP,SMA dan perguruan tinggi tidak lepas dari kegiatan penjadwalan akademik. Penjadwalan akademik merupakan kegiatan rutin dilakukan sebelum masuk tahun ajaran baru. Penjadwalan yang sukses adalah awal dari kelancaran kegiatan akademik. Inti dari penjadwalan adalah menggatur sumberdaya tenaga pendidik, ruang kelas, siswa dan waktu tidakberbenturan. Penjadwalan pada lingkup perguruan tinggi dipandang lebih rumit jika dibandingkan dengan penjadwalan pada jenjang SD,SMP dan SMA. Banyaknya kelas, matakuliah, dan keterbatasan waktu, ruang kelas, dan dosen membuat penjadwalan membutuhkan penanganan yang serius. Permintaan dosen yang mengharuskan mengajar pada hari, jam dan ruang tertentu menambah kerumitan dalam proses penjadwalan perkuliahan.

Kemampuan teknologi menjawab tantangan kesulitan penjadwalan. Tidak sedikit program penjadwalan yang dikembangkan sendiri oleh masing-masing institusi [1] [2] [3] [4] [5] dan ada juga program aplikasi yang dikembangkan secara komersial oleh perusahaan. Dengan menggunakan software aplikasi, penjadwalan akan menjadi lebih cepat. Namun aplikasi penjadwalan yang ada tidak banyak yang terintegrasi menjadi satu kesatuan dengan aplikasi semacam siakad. Sistem informasi akademik atau sering disingkat dengan nama siakad banyak dikembangkan secara terpisah dengan aplikasi penjadwalan. Perusahaan pengembang dan patform yang dipakai juga berbeda. Sehingga muncul gap antara aplikasi menjadwalan dengan palikasi siakad. Permasalahan yang muncul adalah sulitnya distribusi data antara aplikasi penjadwalan menuju aplikasi siakad.

Dalam artikel ini akan dibahas satu sampel aplikasi penjadwalan yang dikembangkan oleh perusahaan komersial yaitu aplikasi asc timetable. Aplikasi asc timetable adalah aplikasi yang berjalan pada komputer desktop dengan platform windows. Aplikasi asc timetable tergolong ringan dan cepat. Penjadwalan yang rumit mampu diselesaikan dengan aplikasi ini. Jika pada institusi kita memiliki aplikasi siakad berbasis web dan mengharuskan data jadwal hasil generate dari asc timetable dimasukan pada aplikasi siakad maka ini akam menjadi masalah. Asc timetable didesain tidak untuk berkomunikasi dengan aplikasi selain dengan aplikasi yang dikeluarkan oleh perusahaan yang sama. Cara yang paling mudah dilakukan adalah melakukan input data jadwal hasil generate dari asc timetable secara menual ke aplikasi siakad. Namun cara ini membutuhkan waktu yang lama sesuai dengan banyaknya data. Cara ini juga memiliki potensi human erroryang tinggi.

Pada artikel ini tertarik untuk menyelesaikan kendala tersebut. Langkah yang akan diambil adalah dengan melakukan pengembangan aplikasi penghubung antara aplikasi asc timetable dengan aplikasi siakad. Aplikasi yang dikembangkan akan mendistribusikan data jadwal dari aplikasi asc timetable menuju aplikasi siakad berbasis web.

\section{METODE PENELITIAN}

Penelitian dilakukan dengan metode classic life cycle [6]seperti ditunjukkan pada Gambar 1. Penjelasan tahapan adalah sebagai berikut:

a. Analisa

Pada tahap analisa dialukan untuk menentukan prinsip kerja dari aplikasi yang akan dikembangkan dan juga untuk mengetahui struktur data dari asc timetable.

b. Desain

Setelah prinsip kerja ditentukan maka tahap berikutnya dilakukan desain aplikasi meliputi desain database dan desain interface

c. Implementasi pada tahap implementasi dilakukan pembuatan aplikasi dengan dengan basis teknologi web.

d. Pengujian

Pegujian dilakukan untuk mengetahui kinerja dari aplikasi yang dikembangkan menggunakan metode black box. 


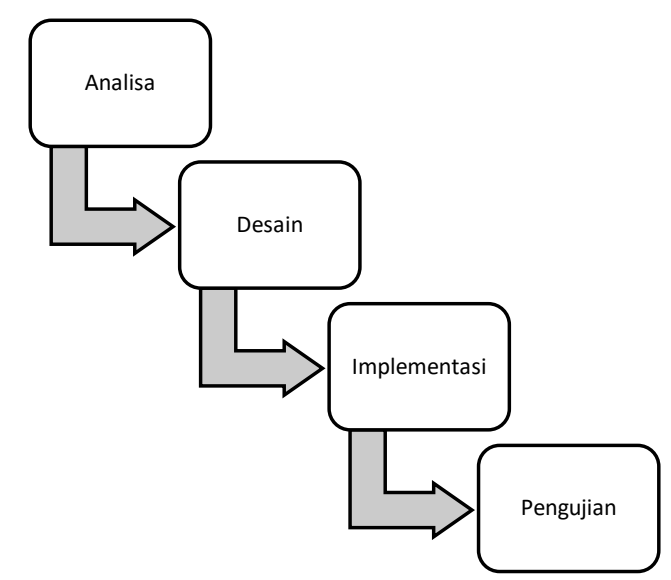

Gambar 1. Diagaram alir metode penelitian

\subsection{Prinsip jalannya aplikasi}

Pada prinsipnya aplikasi yang dikembangkan digunakan untuk mempermudah data jadwal dari aplikasi asc timetable bisa dikirimkan dengan mudah ke database aplikasi siakad. Desain prose distribusi ditunjukan pada Gambar 2.

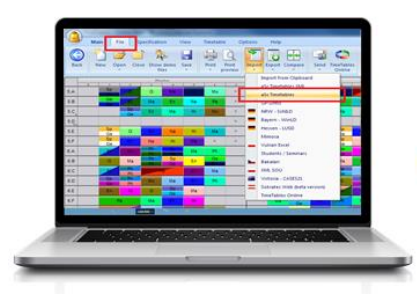

Aplikasi Asc Timetabel

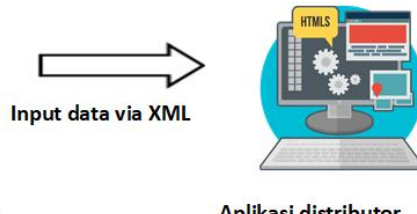

Aplikasi distributor

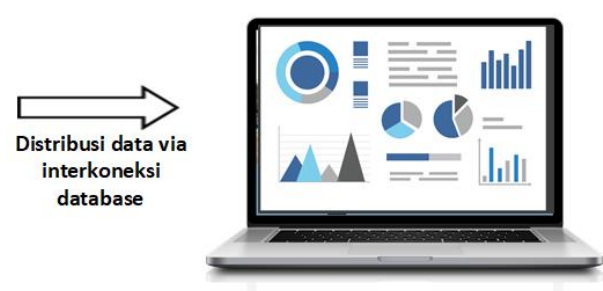

Aplikasi siakad

\section{Gambar 2. Skema proses kerja aplikasi distributor}

Data dari asc timetable diexport dalam format $x m l$. File $x m /$ diupolad ke aplikasi distributor kemudian diextrak dan disimpan kedalam database. data yang telah disimpan didalam database aplikasi dapat diexport ke format excel sesuai dengan struktur data aplikasi siakad. File excel ini dapat digunakan untuk melakukan cek apakah data yang didapat sudah sesuai dengan data pada asc timetable. Data pada database aplikasi distributor dapat dikirimkan ke database siakad dengan menggunakan fasilitas singkronisasi antar database. Agar mudah proses singkronisasi DBMS pada aplikasi distributor disamakan dengan DBMS pada aplikasi siakad.

\subsection{Struktur xmI aplikasi asc timetable}

Struktur data $\mathrm{xm} /$ hasil export dari asc timetable adalah sebagai berikut:

$<$ ?xml version="1.0" encoding="UTF-8"?>

<timetable ascttversion="2020.9.1" importtype="database"

options="export:idprefix: CHRID, import: idprefix: TEMPID, groupstype1, decimalseparatordot, lesson sincludeclasseswithoutstudents, handlestudentsafterlessons" defaultexport="1" displayname="asc

Timetables 2012 XML" displaycountries="">

<periods options="canadd, export:silent" columns="period, name, short, starttime, endtime">

<period name="1" short="1" period="1" starttime="7:00" endtime="7:50"/>

$</$ periods $>$

<daysdefs options="canadd, export:silent" columns="id, days, name, short">

<daysdef id="E76B6218D4125C61" name="Senin" short="Se" days="10000"/>

$</$ daysdefs $>$

<subjects options="canadd, export:silent" columns="id, name, short,partner id">

<subject id="931E24E936B9BEB4" name="PAI - AL QUR`AN" short="INS281201" partner_id=""/>

$</$ subjects $>$

<teachers options="canadd, export:silent"

columns="id, name, short, gender, color, email,mobile, partner_id,firstname, lastname">

<teacher id="50B53DD7FAB9EF91" firstname="budi" lastname="yanto, M.Si." name="budi yanto,

M.Si." short="006" gender="F" color="\#FF0000" email="" mobile="" partner_id=""/> 


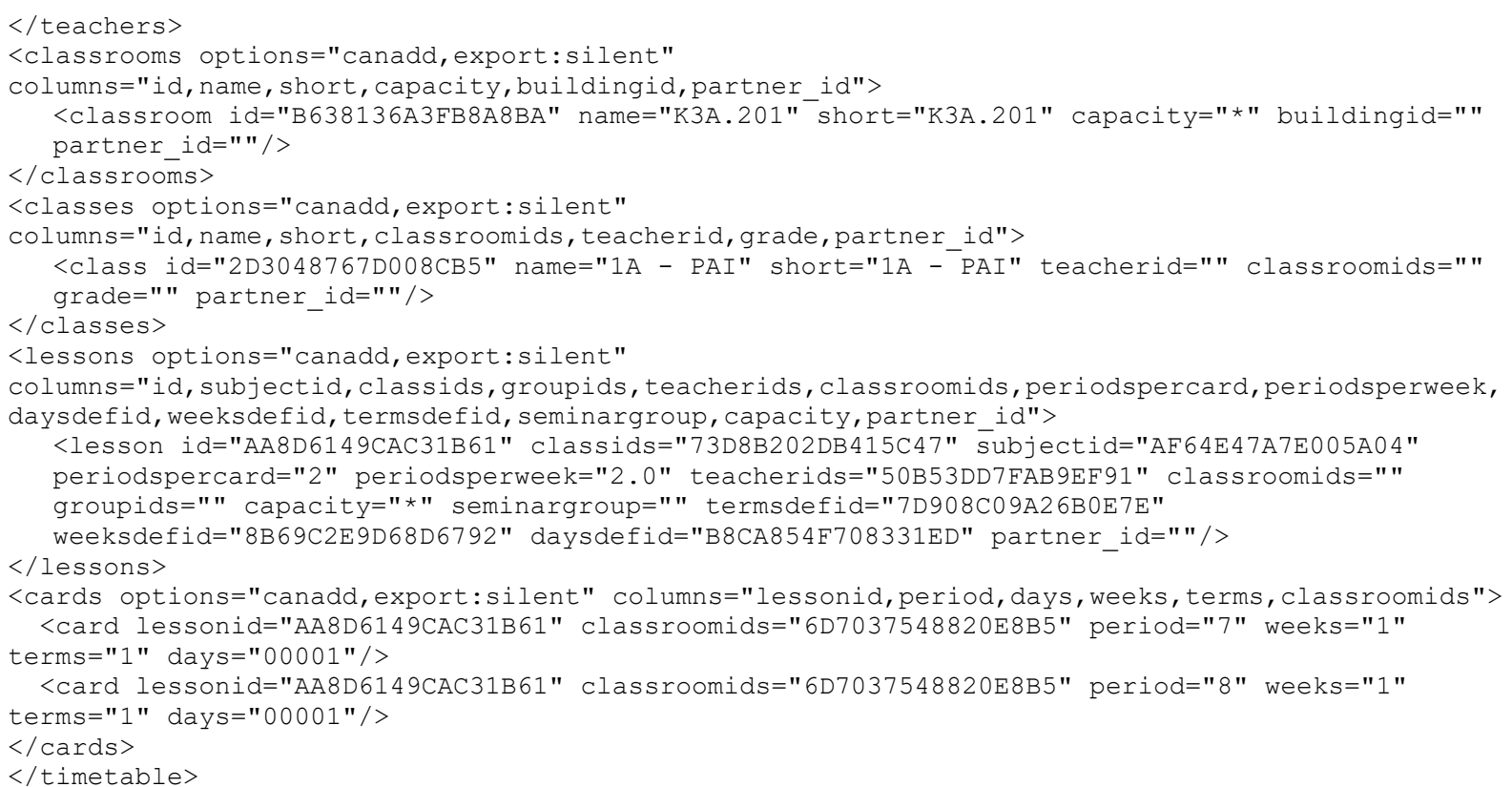

\subsection{Meta data}

Dari struktur $x m / y a n g$ ditunjukkan pada subbab 2.2 terdapat 8 data yaitu periode, hari, ruang kelas, kelas, teacher, plot dosen, dan terakhir adalah jadwal. Setiap data secara detail dijelaskan pada Tabel 1.

Tabel 1. Meta data

\begin{tabular}{lll}
\hline No & Nama data & Diskripsi \\
\hline 1. & Periode & Menyimpan data jam pelajaran dalam setiap hari \\
2. & Hari & Menyimpan hari aktif pembelajaran \\
3. & Mata kuliah & Menyimpan data mata kuliah atau mata pelajaran \\
4. & Ruang kelas & Menyimpan data ruang yang dipakai untuk pembelajaran \\
5. & Teacher & Menyimpan data teacher atau dosen \\
6. & Kelas & Menyimpan data kelas atau kode gelompok romobongan belajar \\
7. & Plot & Menyimpan data plot antara teacher, mata kuliah dan kelas \\
8. & Jadwal & Menyimpan data jadwal pembelajaran yang meliputi kode plot, data hari, data \\
& & periode dan ruang \\
\hline
\end{tabular}

\subsection{Entity Relationship Diagram (ERD)}

Dari meta data dapat dibuat desain database seperti ditunjukkan pada Gambar 3.

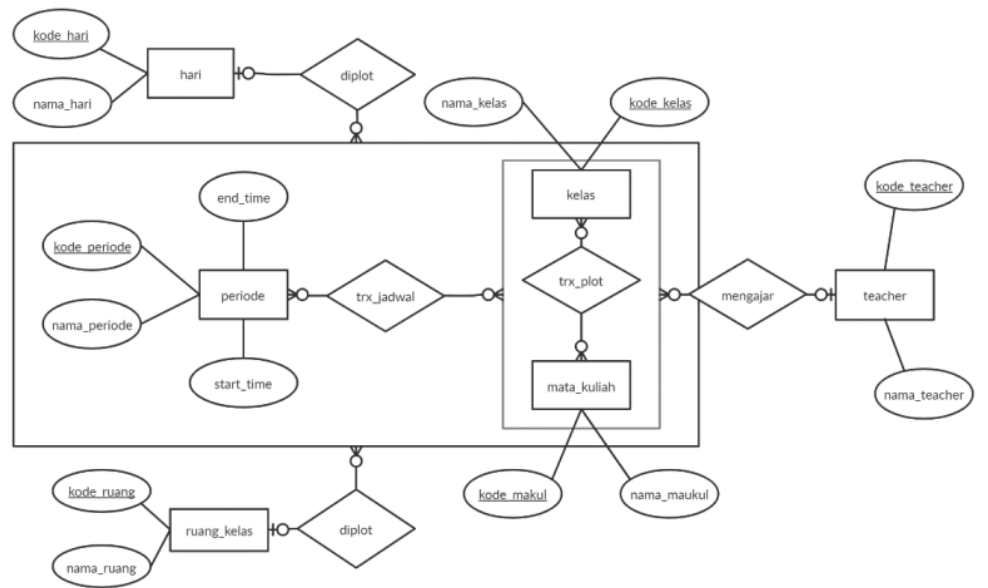

Gambar 3. Entity Relationship Diagram (ERD) 


\subsection{Kebutuhan fungsional dan use case diagram}

Kebutuhan fungsional dan use case digunakan untuk acuan desain operasional aplikasi yang dikembangkan. Aplikasi yang dikembangkan cukup menggunakan satu aktor yaitu disebut dengan nama admin. Kebutuhan fungsional ditunjukkan pada Tabel 2 dan use case diagaram ditunjukkan pada Gambar 4.

Tabel 2. Kebutuhan fungsional

\begin{tabular}{lll}
\hline Kode & Deskripsi & Aktor \\
\hline FR01 & Sitem dapat melakukan reset data & admin \\
FR02 & Sistem dapat melakukan upload file xml & admin \\
FR03 & Sistem dapat membaca file xml & admin \\
FR04 & Sistem dapat dan ekstrak data xml dan & admin \\
& $\begin{array}{l}\text { menyimpannya di database } \\
\text { FR05 }\end{array}$ & Sistem dapat mengkonversi dari database menuju \\
& format excel & admin \\
\hline
\end{tabular}

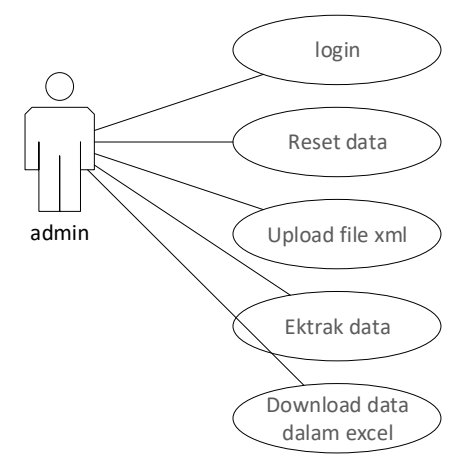

Gambar 4. Use case diagaram

\section{HASIL DAN PEMBAHASAN}

Aplikasi distribusi data dari asc timetable menuju siakad dikembangkan menggunakan teknologi berbasis web. Pembuatannya menggunakan bahasa pemprograman $p h p$ dan DBMS yang digunakan adalah mysql. Aplikasi hanya didesain satu aktor. Alur penggunaan aplikasi dijelaskan dalam flowchartyang ditunjukkan pada Gambar5.

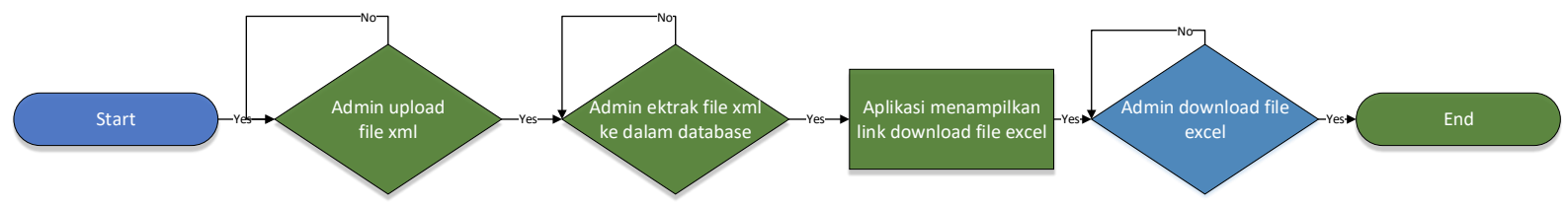

\subsection{Tampilan aplikasi}

Gambar 5. flowchart

Sesuai dengan flowchart yang ditunjukkan Gambar 5 , tampilan tahapan pertama dalah upload file $\mathrm{xmI}$. File $\mathrm{xmI}$ diperoleh dari aplikasi asc timetable. Form upload file xml ditunjukkan pada Gambar 6. Ukuran file tidak dibatasi. Format file yang dapat diproses hanyalah ${ }^{*} . x m l$. 


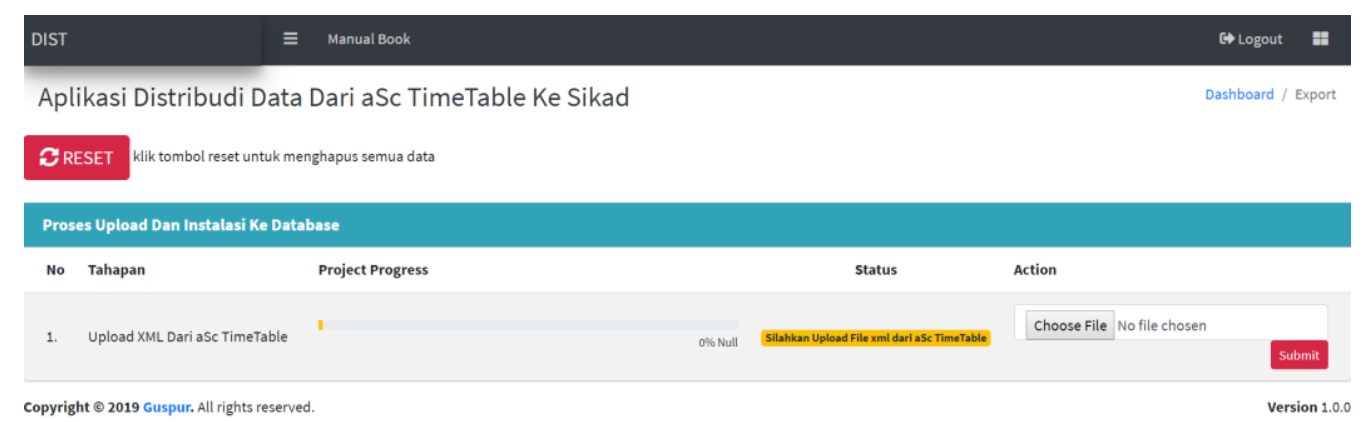

\section{Gambar 6. Upload file xml}

Ketika file berhasil dikirim maka akan muncul tampilan install data kedalam database seperti ditunjukan pada Gambar 7. Proses install atau ektrak data dari file $\mathrm{xml}$ asc timetable ke database membutuhkan waktu sesuai banyaknya data.

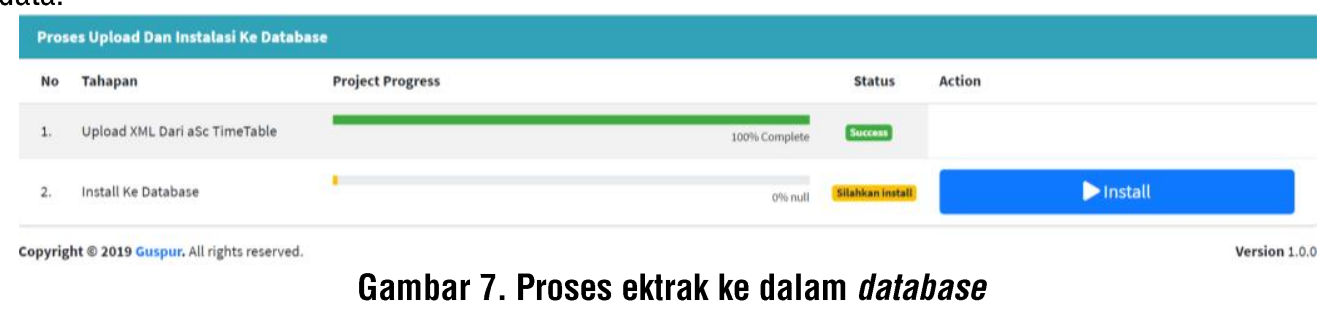

Jika file berhasil diektrak dan disimpan dalam database maka akan muncul tampilan download file excel dalm format yang mudah dibaca. Ditunjukkan pada Gambar 8.

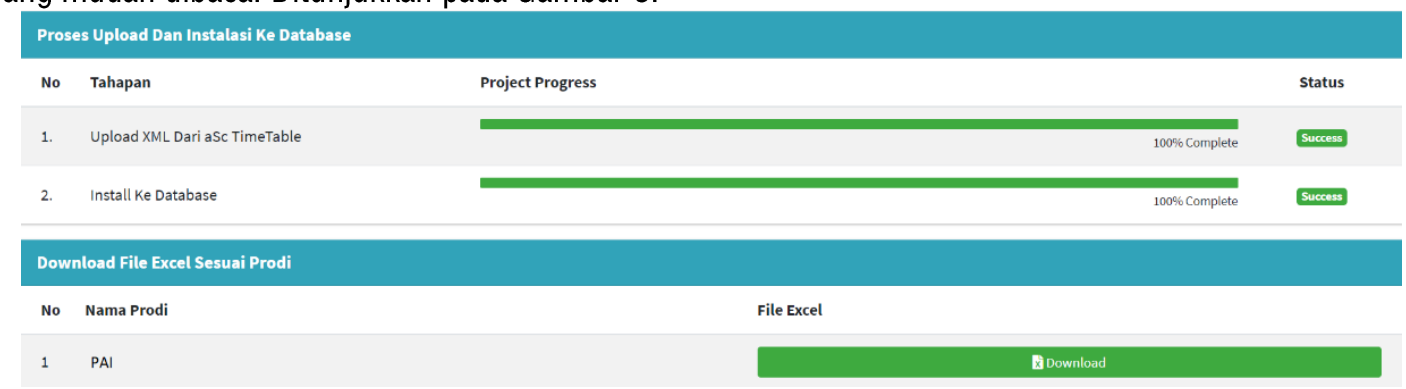

Gambar 8. Download file excel

\subsection{Pengujian aplikasi}

Teknik pengujian yang dilakukan adalah dengan metode black-box testing. Black-box testing cocok digunakan untuk pengujian perangkat lunak yang menekankan pada spesifikasi fungsionalnya [7] [8] . Keuntungan menggunakan metode pengujian dengan black-box testing adalah membantu untuk memunculkan inkonsistensi dengan spesifikasi persyaratan yang telah ditetapkan [9]. Hasil pengujian black-box ditunjukkan pada Tabel 3.

Tabel 3. Hasil pengujian black-box

\begin{tabular}{|c|c|c|c|c|}
\hline No & Skenario pengujian & Hasil yang diharapkan & Hasil Pengujian & Kesimpulan \\
\hline 1. & Proses login & $\begin{array}{l}\text { Jika username dan password salah } \\
\text { maka tidak bisa masuk ke dashboard } \\
\text { jika benar maka masuk ke dashboard }\end{array}$ & Sesuai Harapan & Valid \\
\hline 2. & Prses reset data & $\begin{array}{l}\text { Jika klik tombol reset maka data di } \\
\text { dalam database akan kembali ke awal }\end{array}$ & Sesuai Harapan & Valid \\
\hline 3. & $\begin{array}{l}\text { Proses upload xml dari } \\
\text { asc timetable }\end{array}$ & File $x m /$ bisa tersimpan pada aplikasi & Sesuai Harapan & Valid \\
\hline 4. & $\begin{array}{l}\text { Proses install ke } \\
\text { database }\end{array}$ & $\begin{array}{l}\text { File } x m / \text { yang telah diupload berhasil } \\
\text { di ektrak dan datanya bisa terinstall ke } \\
\text { database }\end{array}$ & Sesuai Harapan & Valid \\
\hline
\end{tabular}




\begin{tabular}{llll}
\hline 5. $\begin{array}{l}\text { Download file excel tiap } \\
\text { prodi }\end{array}$ & $\begin{array}{l}\text { Data jadwal yang telah berhasil masuk } \\
\text { ke databse bisa di Tarik dalam bentuk } \\
\text { file excel }\end{array}$ & Sesuai Harapan & Valid \\
\hline
\end{tabular}

Dari hasil pengujian black-box tidak ditemukan inkonsistensi dengan spesifikasi persyaratan yang telah ditetapkan. Semua fungsional berjalan dengan sempurna. Data yang direkam dalam format excel sama dengan data yang disertakan pada file $\mathrm{xml}$.

\subsection{Pengujian dari segi penguna}

Pengujian dari segi pengguna dimaksudkan untuk mengetahui seberapa efektif dan efisien aplikasi ini membantu kerja dalam proses konversi dari data asc timetable menuju siakad. Dalam pengujian ini menggunakan data jadwal yang dimiliki oleh fakultas tarbiyah IAIN Salatiga. Pada fakultas tarbiyah IAIN Salatiga rata-rata setiap semester memiliki data perkuliahan 1305. Jika ektrak data asc timetable secara manual dan setiap data membutuhkan waktu 0.5 menit maka dibutuhkan waktu sebanyak 652.5 menit atau 10.8 jam. Jika ekstrak data menggunakan aplikasi yang dikembangkan hanya membutuhkan waktu antara $3 \mathrm{~s} / \mathrm{d} 5$ menit. Perbandingan kedua teknik ini lebih jelas ditunjukkan pada gambar 9.

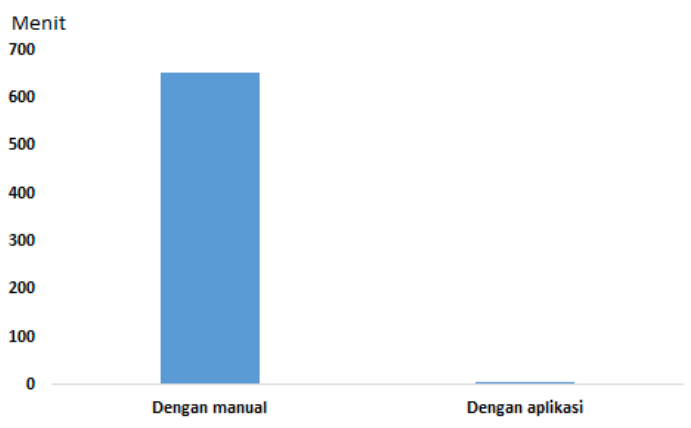

Gambar 9 Grafik perbandingan hasil uji antara metode ektrak data dengan manual dengan aplikasi

Berdarkan grafik yang ditunjukan pada Gambar 9, aplikasi yang dikembangkan mendukung efisiensi waktu kerja yang tinggi yaitu sebesar $99 \%$ dan efektifitas yang tinggi karena dapat menghasilkan data yang sesuai diharapkan dan minim akan human error.

\section{KESIMPULAN}

Bedasarkan pembahasan dan pengujian, aplikasi yang dikembangkan telah berjalan sesuai dengan perancangan. Aplikasi yang dikembangkan memiliki fitur utama yaitu ektrak data dari format $\mathrm{xm} /$ asc timetable menuju format $s q /$ dan excel. Data dari excel mudah untuk dibaca oleh operator dan format $s q /$ mudah untuk didistribusikan dalam aplikasi siakad. Berdasarkan pengujian pengguna, aplikasi ini menunjukkan efisiensi dan efektifitas waktu yang tinggi yaitu sebesar $99 \%$. Sehingga aplikasi yang dikembangkan dapat mempercepat keja kususnya dalam proses penjadwalan yang menggunakan aplikasi asc timetable.

\section{UCAPAN TERIMA KASIH}

Terima kasih kami ucapkan kepada akademik fakultas tarbiyah dan ilmu keguruan IAIN Salatiga yang telah mendukung pengembangan aplikasi distribusi dari asc timetable menuju aplikasi siakad.

\section{DAFTAR PUSTAKA}

[1] A. T. Laksono, M. C. Utami and Y. Sugiarti, "Sistem Penjadwalan Kuliah Menggunakan Metode Algoritma Genetika (Studi Kasus: Fakultas Kedokteran Dan Kesehatan Universitas Muhammadiyah Jakarta)," Studia Informatika: Jurnal Sistem Informasi, vol. 9, no. 2, pp. 177-188, 2016.

[2] Y. Sari, M. Alkaff, E. S. Wijaya, S. Soraya and D. P. Kartikasari, "Optimasi Penjadwalan Mata Kuliah Menggunakan Metode Algoritma Genetika Dengan Teknik Tournament Selection," Jurnal Teknologi Informasi dan IImu Komputer (JTIIK), vol. 6, no. 1, pp. 85-p2, 2018. 
[3] M. Yulistiana, D. Chaerani and E. Lesmana, "Penerapan Metode Hungarian dalam Penentuan Penjadwalan Matakuliah Optimal (Studi Kasus: Departemen Matematika Universitas Padjadjaran Semester Ganjil 20132014)," Jurnal Matematika Integratif, vol. 11, no. 1, pp. 45-64, 2015.

[4] L. D. Setia, "Implementasi Sistem Penjadwalan Mata Kuliah Berbasis Web," Jurnal IImiah Informatika , vol. 2, no. 1, pp. 117-120, 2017.

[5] M. Nugraha and Y. Nugraha, "Selamat Tinggal Bentrok! Efisiensi Pengelolaan Jadwal Kuliah dengan SIMDRaW(Sistem Informasi Manajemen Dosen, Ruang, dan Waktu)," Fountain of Informatics Journal , vol. 3, no. 1, pp. 24-29, 2018.

[6] R. S. Pressman, Rekayasa perangkat lunak: pendekatan praktisi (edisi 7), Yogyakarta: Andi Publisher, 2012.

[7] S. R. Jan, S. T. U. Shah, Z. U. Johar, Y. Shah and F. Khan, "An Innovative Approach to Investigate Various Software Testing Techniques and Strategies," Int. J. Sci. Res. Sci. Eng., vol. 2, no. 2, pp. 682-689, 2016.

[8] J. Watkins, Testing IT An Off The Shelf Software Testing, 2001.

[9] P. Ammann, J. Offutt and I. Version, Introduction to Software Testing Edition 2 Paul Ammann and Jeff Offutt Instructor Version, 2016. 